\title{
Intact removal of seven metal stents from the bile duct in a single endoscopic session
}

An 89-year-old woman who had undergone placement of multiple uncovered biliary metal stents (Wallstent; Boston Scientific, Natick, Massachusetts, USA) over the previous 10 years for an indeterminate distal common bile duct (CBD) stricture was referred to us for an attempt at removal of the stents. She had recently been undergoing monthly sessions of endoscopic retrograde cholangiopancreatography (ERCP) to clean the stents as treatment of recurrent cholangitis.

A computed tomography (CT) scan demonstrated the severely dilated biliary tree with multiple self-expandable metal stents (SEMSs) in the distal CBD. During ERCP, a large amount of food debris and tissue ingrowth was noted. The debris was removed by vigorous irrigation with sterile water. The distal ends of the stents (those nearest the ampulla) were embedded in the CBD wall and ampulla. The ingrown tissue was ablated by multipolar electrocoagulation (MPEC) with a 7-Fr probe. The innermost stent was grasped just above its distal end and gently extracted using a combination of a rat-tooth forceps and snare. The sequence of tissue ablation followed by stent extraction was repeated from the innermost to the outermost stent. The last stent to be removed was deeply embedded at its distal end and required removal by eversion (the proximal end was grasped with a rattooth forceps and pulled down through the center of the stent, thereby everting the stent and "peeling" it off the CBD wall).

The removal of all seven intact stents was achieved in one session ( Fig. 1 and - Fig. 2; Video 1).

Balloon-assisted cholangioscopy with a diagnostic gastroscope confirmed that the entire duct had been cleared atraumatically. A single residual, small embedded metal filament was noted and removed using a biopsy forceps. No complications occurred. The patient remained asymptomatic at 2 months.

Uncovered SEMS are contraindicated in benign biliary strictures and in those patients whose life-expectancy is good; this is because of the eventual failure of the stent due to the penetration of the submucosa by the mesh with resultant mucosal hyperplasia and tissue ingrowth [1]. Pre- vious reports have described the removal of mainly single uncovered SEMS, with fragile Wallstents often removed by piecemeal extraction of wire filaments [2-6]. Use of a covered SEMS to decrease tissue ingrowth and facilitate removal of uncovered SEMS has also been reported [6].

We describe a new technique whereby seven SEMS, all but one uncovered, were removed intact in a single session. Ingrown tissue was ablated with MPEC rather than argon plasma coagulation to avoid damage to and disintegration of the SEMS, which would have required laborious piecemeal removal. The stents were grasped in a way that avoided any fraying of the distal struts of the Wallstents, which thereby maintained their integrity during extraction. The outermost stent required eversion for intact extraction because of the degree to which it had become embedded.

\section{Video 1}

Endoscopic technique for intact removal of multiple metal stents from the bile duct in a single session.

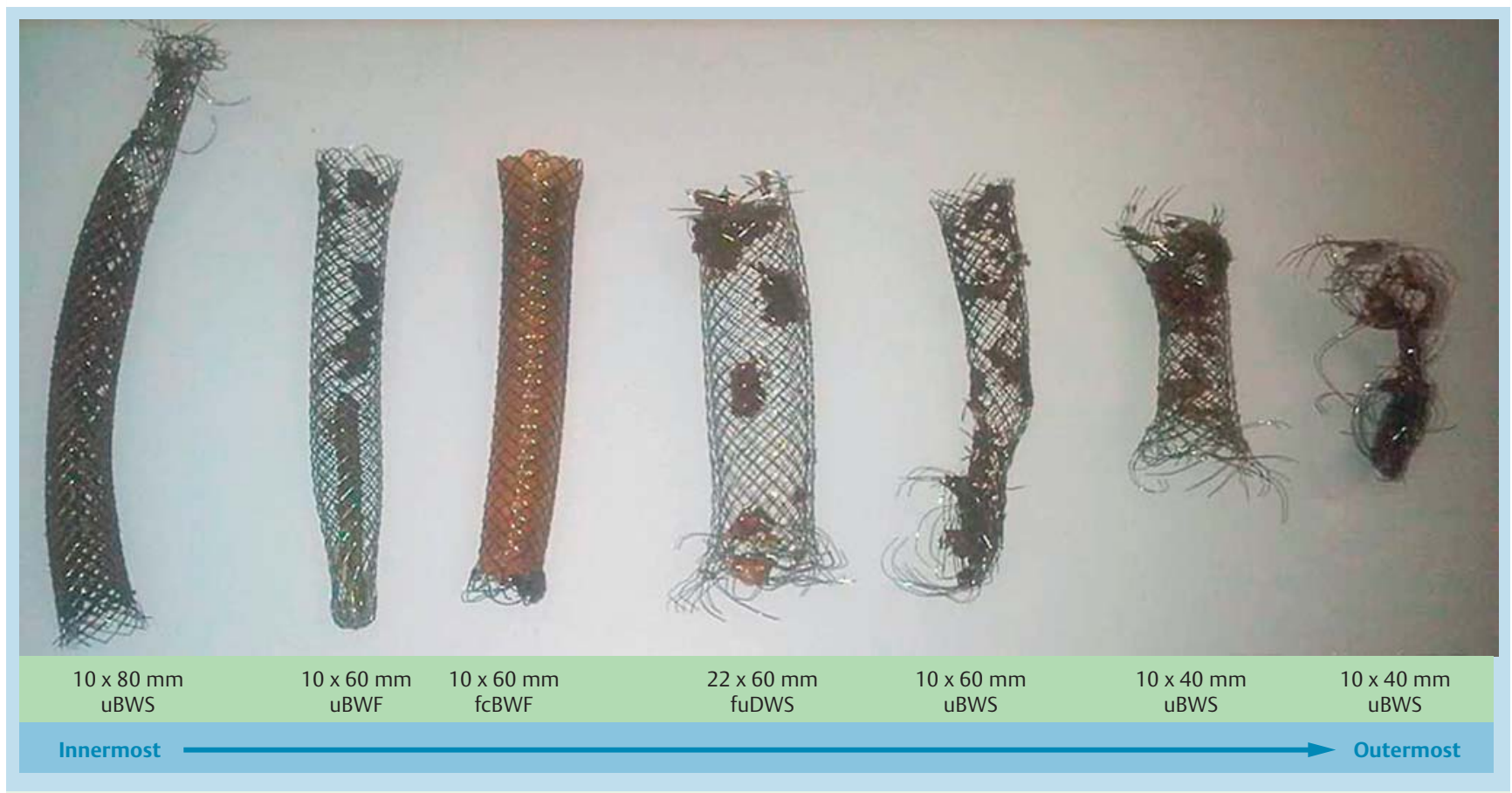

Fig. 1 The seven metal stents that were removed intact from the bile duct in a single endoscopic session. uBWS, uncovered biliary Wallstent; uBWF, uncovered biliary Wallflex; fcBWF, fully covered biliary Wallflex; uDWS, uncovered duodenal Wallstent. 


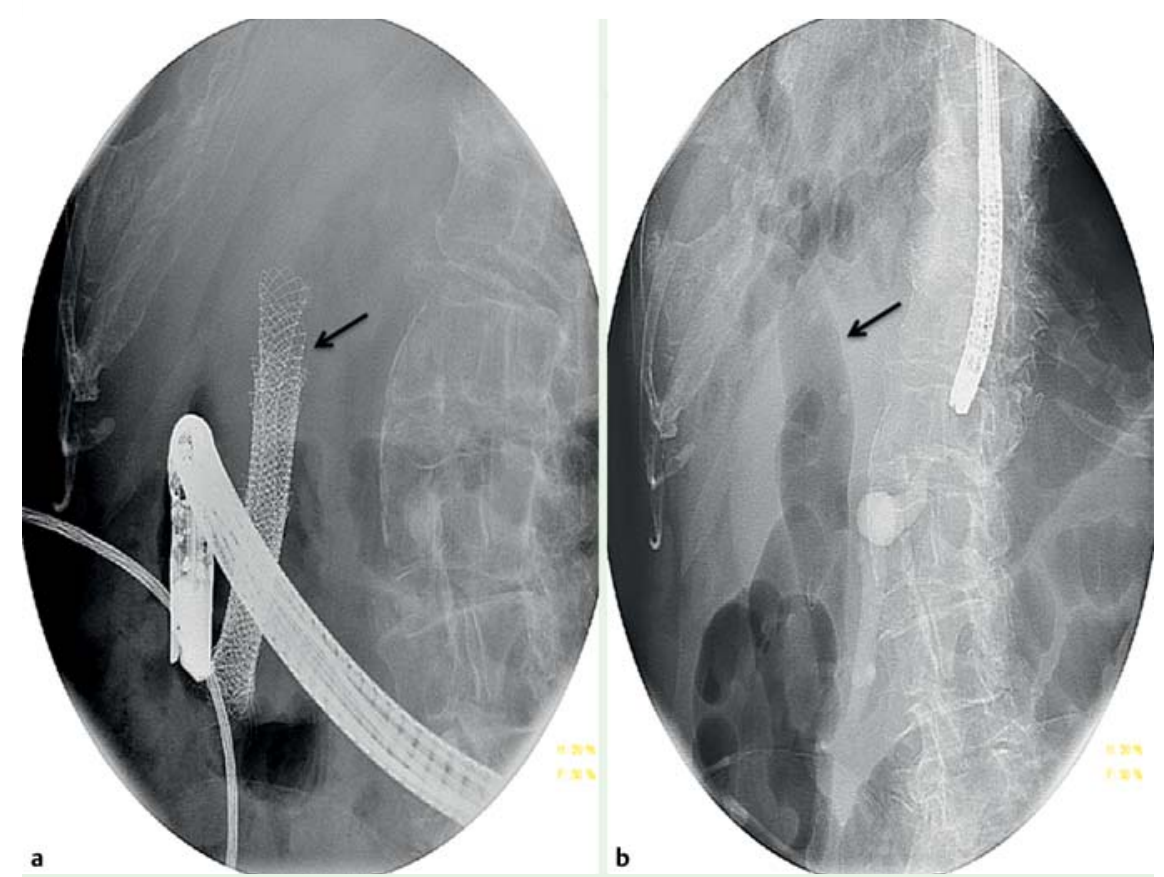

Fig. 2 Fluoroscopic view of the biliary tree: a before removal of the multiple metal biliary stents (arrow indicates the multiple stents in the common bile duct); $\mathbf{b}$ after complete removal of the multiple metal biliary stents (arrow indicates the air cholangiogram).

Endoscopy_UCTN_Code_TTT_1AR_2AZ

Competing interests: None
S. Iqbal, T. C. Pitea, S. N. Stavropoulos Department of Medicine, Division of Gastroenterology, Winthrop University Hospital, Mineola, New York, USA

\section{References}

1 Hausegger KA, Kleinert R, Lammer J et al. Malignant biliary obstruction: histologic findings after treatment with self-expandable stents. Radiology 1992; 185: 461 - 464

2 Ahmed A, Keeffe EB, Imperial JC. A novel technique for endoscopic removal of expandable biliary Wallstent. Gastrointest Endosc 1999; 50: $279-281$

3 Egan LJ, Baron TH. Endoscopic removal of an embedded biliary Wallstent by piecemeal extraction. Endoscopy 2000; 32: 492 - 494

4 Levy MJ, Wiersema MJ. Endoscopic removal of a biliary Wallstent with a suture-cutting device in a patient with primary pancreatic lymphoma. Endoscopy 2002; 34: 835-837

5 Kahaleh M, Tokar J, Le T et al. Removal of selfexpandable metallic Wallstents. Gastrointest Endosc 2004; 60: 640 - 644

6 Lahlal M, Gigot JF, Annet L, Deprez PH. Successful endoscopic extraction of a double uncovered expandable metal stent. Endoscopy 2009; 41: $98-99$

\section{Bibliography}

DOI $10.1055 / \mathrm{s}-0030-1257044$

Endoscopy 2011; 43: E413-E414

(c) Georg Thieme Verlag KG Stuttgart · New York . ISSN 0013-726X

\section{Corresponding author}

S. Iqbal, MD

Department of Medicine, Division of Gastroenterology, Winthrop University Hospital 222 Station Plaza North, Suite 429

Mineola

New York 11501

USA

Fax: +1-516-663-4617

siqbal50@gmail.com 